\title{
MỐI TƯƠNG QUAN GIỮA LƯU LƯỢNG, PH VÀ KHẢ NĂNG ĐỆM CỦA NƯỚC BỌT SAU KHI SỬ DỤNG KEO CAO SU XYLITOL
}

\section{TÓM TẮT}

Mục tiêu: Nghiên cứu can thiệp không đối chứng thực hiện tại trường Đại học Y Dược Thái Nguyên với mục đích đánh giá tương quan giữa các đại lượng: lưu lượng, $\mathrm{pH}$ và khả năng đệm của nước bọt trước sau khi sử dụng kẹo cao su xylitol. Đối tượng và phương pháp: 43 sinh viên đảm bảo tiêu chuẩn và đồng ý tham gia nghiên cứu. Các mấu nước bọt được lấy ở trạng thái nghỉ và sau khi nhai xylitol, sau đó được đo lưu lượng theo quy trình chuẩn, đo khả năng đệm, xác định pH bằng máy đo Hana tại trạng thái nghỉ và sau khi nhai kẹo cao su xylitol 5 phút. Sau đó so sánh cặp các kết quả. Kết quả: Ở trạng thái nghỉ, có sự khác biệt đáng kể về lưu lượng dòng chảy và $\mathrm{pH}$ so với khả năng đệm $(p=0.000)$, cự thể lưu lượng nhỏ hơn giá tri về khả năng đẹm trung bình 3.85767 , trong khi $\mathrm{pH}$ thì lớn hơn trung bình 2.52265. Ở trạng thái kích thích, do cả pH và lưu lượng đều tăng, nên các rút ngắn khoảng cách giữa lưu lượng và khả năng đệm (1.72395) và tăng giá trị trung bình của cặp còn lại (2.52302). Kết luận: Nghiên cứu cho thây sự tăng pH và lưu lương nước bot sau khi nhai keo cao su xylitol, so sánh với khả nằng đệmgóp phân tăng sức khỏe răng miệng và phòng ngừa nguy cơ sâu răng.

Tư khóa: Nước bọt, pH, lưu lượng, kẹo cao su xylitol, khả năng đệm

\section{SUMMARY \\ CORRELATION BETWEEN VARIABLES: SALIVARY FLOW RATE, PH AND BUFFER CAPACITY AFTER CHEWING XYLITOL}

Objective: A quasi- experimental study was conducted in Thai Nguyen University of Medicine and Pharmacy in order to evaluatecorrelations between salivary flow rate, $\mathrm{pH}$ as well as buffer capacity before and after chewing xylitol gum. Subject and method: Whole mouth saliva was collected from 43 volunteers who met inclusion criteria and gave informed consent. After unstimulated saliva was collected, stimulated saliva was collected at intervals during each 5 min of xylitol chewing. The salivary flow and $\mathrm{pH}$ were measured for each sample. Result: At rest, unstimulated salivary flow rate was statistically significant lower than buffer capacity $(p=0.000)$. In contract, $\mathrm{pH}$ of unstimulated saliva was higher than buffer capacity $(p=0.000)$. After chewing xylitol, due to increasing $\mathrm{pH}$ and saliva flow, the differences between $\mathrm{pH}$, saliva flow long in comparison with buffer capacity rise considerably, with 2.52302 and

*Trường Đại học Y Dước Thái Nguyên

Chịu trách nhiệm chính: Trần Phương Nga

Email: ngatran21rhm@gmail.com

Ngày nhận bài: $1 / 9 / 2021$

Ngày phản biên khoa học: 27/9/2021

Ngày duyệt bài: 7/10/2021

\section{Trần Phương Nga*, Lê Thị Thu Hằng*}

1.72395 respectively. Conclusion: The increased salivary $\mathrm{pH}$ and flow with xylitol gum may have implications for oral health and prevent of dental caries

Keywords: Salivary, pH, flow rate, xylitol, buffer capacity.

\section{I. ĐĂT VẤN ĐỀ}

Sâu răng là bệnh lý phổ biến, gây ảnh hưởng đến sức khỏe răng miệng nói riêng và sức khỏe toàn thân nói chung. Tố chức $Y$ tế Thế giới đã xếp nó vào tai họa thứ 3 của loài người chỉ sau ung thu và tim mach [7]. Tại Việt Nam, theo thống kê từ Cục $Y$ tế dự phòng năm 2011 cũng cho thây trên $80 \%$ học sinh tiểu học Việt Nam mắc các bệnh răng miệng như sâu răng, viêm quanh răng, ở lứa tuổi lớn hơn tỷ lệ này cũng lên đến $60-70 \%$ và đang có dấu hiệu tăng lên trong thời gian gần đây [1]. Với chiến lược phòng bệnh hơn chữa bệnh, các nghiên cứu được tiến hành để tìm ra nhứng giả pháp ngăn ngừa cắn bệnh này.

Nước bọt là một trong những yếu tố quan trọng có mặt trong sơ đồ cơ chế gây sâu răng nển việc tác động vào nước bọt để làm giảm nguy cơ gây sâu răng cũng đã được đề cập. Chất lượng và số lượng nước bọt đóng vai trò quan trọng trong trạng thái cân bằng trong khoang miệng (Leone CW, 2001)[5]. Khi giảm các yếu tố như $\mathrm{pH}$, lưu lượng, khả năng đệm sẽ làm tăng nguy cơ mắc bệnh răng miệng.

Các tác nhân kích thích nước bot được coi là có vai trò trong phòng và điều trị bệnh sầu răng, điển hình trong số đó là kẹo cao su xylitol. Đây là biện pháp có tính khả thi cao để áp dụng trong cộng đồng. Tuy nhiên, việc nghiên cứu về tác động của kẹo cao su xylitol cụ thể tới lưu lượng, $\mathrm{pH}$ và khả năng đệm của nước bọt vẫn còn hạn chế, đặc biệt là ở Việt Nam. Vì vậy chúng tôi thực hiện nghiên cứu nhẳm đánh giá mối tương quan giữa lưu lượng, $\mathrm{pH}$ và khả năng đệm của nước bọt khi sử dụng kẹo cao su xylitol.

II. ĐỐI TƯỢNG VÀ PHƯƠNG PHÁP NGHIÊN CỨU

2.1. Đối tượng nghiên cứu: Sinh viên Răng Hàm Mặt, Trường Đại học $Y$ Dược Thái Nguyên

2.2. Địa điểm và thời gian nghiên cứu: Từ 3/2020 đến 4/2021 tại Trường Đại học Y Dược Thái Nguyên

\subsection{Phương pháp nghiên cứu:}

- Thiết kế nghiên cứu: Nghiên cứu can thiệp không đối chứng 
- Chọn mẫu: Sinh viên đồng ý tham gia nghiên cứu, có chỉ số DMFT < 3 (theo tiêu chuẩn của WHO) và $\mathrm{OHI}-\mathrm{S}<1,2$ được lựa chọn vào nghiên cứu. Những người đang mắc các bệnh nhiễm trùng cấp tính hoặc các bệnh mạn tính có liên quan đến sức khỏe toàn thân hoặc tuyến nước bọt, đã và đang sử dụng các loại thuốc kháng sinh, thuốc giao cảm hoặc thuốc có tác dụng phụ làm tăng giảm tiết nước bọt hoặc thay đổi pH nước bọt trong 2 tháng; điều trị chiếu xạ vùng đầu mặt cổ trong 3 tháng gần thời điểm lấy mẫu bị loại trừ. Trong tổng số 56 sinh viên đồng ý tham gia nghiên cứu có 47 sinh viên đáp ứng đủ tiêu chuẩn và được lựa chọn. Trong 47 sinh viên tham gia lấy mẫu có 44 mẫu đạt và 3 mẫu không đạt do lượng nước bọt ở trạng thái nghỉ ít hơn $0,2 \mathrm{ml}$ là lượng nước bọt tối thiểu để máy đo pH có thể đo được kết quả chính xác.

2.4. Chỉ số nghiên cứu: Các thông tin chung của đối tượng nghiên cứu được thu thập qua phỏng vấn trực tiếp bằng phiếu được thiết kế sằn. Mẫu nước bọt ở trạng thái nghỉ và sau nhai keo cao su xylitol được thu thập theo quy trình chuẩn. Đối tượng được lựa chọn vào nghiên cứu được làm sạch cao răng trước ngày lấy mẫu nước bọt. Trong ngày thực hiện lấy mẫu, bệnh nhân được yêu cầu không sử dụng các loại đồ ăn trước thời điểm lấy mẫu 8 tiếng. Tất cả mẫu đều được lấy vào buổi sáng để đảm bảo yêu cầu và giảm thiểu sai số. Lưu lương nước bọt được xác định bằng milliliter/phút có sử dụng cốc chia vạch và đồng hồ bấm giờ. $\mathrm{pH}$ nước bọt được xác định bằng máy đo Hanna $\mathrm{pH}$ meter. Khả năng đệm của nước bọt cũng được xác định. Các thông số được đo tại trạng thái nghỉ và sai khi nhai kẹo cao su xylitol 5 phút.

2.5. Kỹ thuật thu thập số liệu: Phỏng vấn, khám răng miệng, thu thập mẫu nước bọt được thực hiện bởi 2 bác sĩ Rằng Hàm Mắt và 1 kỹ thuật viên đã được tập huấn. Tất cả các thông in trên được thu thập và điên vào phiếu thiết kế sẵn.

2.6. Xử lý số liệu: Số liệu được xử lý bằng các thuật toán thống kê y học. Giá trị trung bình, tỉ lệ phần trăm, $t$-test đã được sử dụng.

2.7. Đạo đức nghiên cứu: Nghiên cứu đã được Hội đồng Đạo đức nghiên cứu y sinh học trường Đại học $Y$ Dược Thái Nguyên phê duyệt (số 239/ĐHYD-HĐĐĐ )

\section{KẾT QUẢ NGHIÊN CỨU}

Bảng 1. Mô tả khả năng đệm của nước bọt

\begin{tabular}{|c|c|c|}
\hline Khả năng đệm & $\mathbf{n}$ & $\mathbf{\%}$ \\
\hline Giá trị & & \\
\hline Rất thấp & 12 & 27.9 \\
\hline
\end{tabular}

\begin{tabular}{|c|c|c|}
\hline Thấp & 12 & 27.9 \\
\hline Bình thường & 4 & 9.3 \\
\hline Cao & 15 & 34.9 \\
\hline Tống & $\mathbf{4 3}$ & $\mathbf{1 0 0 . 0}$ \\
\hline
\end{tabular}

Bảng số liệu về khả năng đệm của nước bọt cho thấy khả năng đệm thấp và rất thấp chiếm đa số là $55.8 \%$, giá trị bình thường chỉ chiếm $9.3 \%$ và giá trị cao chiếm $34.9 \%$.

Bảng 2. Mối tương quan giữa lưu lượng nước bọt-khả năng đệm của nước bọt ở trạng thái nghi.

\begin{tabular}{|c|c|c|c|}
\hline Trạng thái nghí & $\mathbf{X} \pm$ & SD & $\mathbf{p}$ \\
\hline Lưu lượng nước bọt & $0.47 \pm$ & 0.24 & $<0.0$ \\
\hline Khả năng đệm & $4.33 \pm$ & 1.13 & 01 \\
\hline
\end{tabular}

Khi so sánh khả năng đệm của nước bọt và lưu lượng nước bọt ở trang thái nghi, kết quả $\mathrm{p}$ $<0.001$, cho thấy sự khác biệt có ý nghĩa thống kê giữa 2 đại lượng.

Bảng 3. Mồi tương quan giữa pH nước bọt khả năng đệm của nước bọt ở trạng thái nghi'

\begin{tabular}{|c|c|c|c|}
\hline Trạng thái nghỉ & $\mathbf{X \pm}$ & SD & p \\
\cline { 1 - 3 } pH nước bọt & $6.85 \pm$ & 0.55 & $<0.0$ \\
\cline { 1 - 2 } $\begin{array}{c}\text { Khả năng đềm } \\
\text { của nước bọt }\end{array}$ & $4.33 \pm$ & 1.13 & 01 \\
\hline
\end{tabular}

Tương tự, ở trang thái nghỉ, $\mathrm{pH}$ và khả năng đêm có giá trị khác biệt đáng kể với $\mathrm{p}<0.001$, với $\mathrm{pH}$ có giá trị trung bình $6.85 \pm 0.55$, và khả năng đệm $4.33 \pm 1.13$.

Bảng 4. Môi tương quan giữa lưu lượng nước bọt - khả năng đệm của nước bọt sau nhai kẹo xylitol 5 phút.

\begin{tabular}{|c|c|c|c|}
\hline $\begin{array}{c}\text { Sau nhai kẹo cao } \\
\text { su xylitol 5 phút }\end{array}$ & $\mathbf{X} \pm$ & SD & $\mathbf{p}$ \\
\hline Lưu lượng nước bọt & $2.85 \pm$ & 0.90 & $<0.0$ \\
\hline $\begin{array}{c}\text { Khả nằng đệm của } \\
\text { nước bọt }\end{array}$ & $4.57 \pm$ & 0.81 & 01 \\
\hline
\end{tabular}

So sánh cắp về lưu lượng nước bọt và khả năng đệm của nước bọt sau nhai kẹo cao su xylitol trong 5 phút. Sự khác biệt tiếp tục có ý nghĩa thống kê $(p<0.001)$, cả lưu lượng và khả năng đệm đều tăng so với thời điểm ban đầu.

Bảng 5. Mối tướng quan giữa $p H$ nước bot khả năng đệm của nước bọt sau nhai kẹo xylitol 5 phút.

\begin{tabular}{|c|c|c|c|}
\hline $\begin{array}{c}\text { Sau nhai keo cao } \\
\text { su xylitol 5 phút }\end{array}$ & $\mathbf{X} \pm$ & SD & $\mathbf{p}$ \\
\hline pH nước bọt & $7.09 \pm$ & 0.34 & \multirow{2}{*}{$<0}$. \\
\cline { 1 - 2 } $\begin{array}{c}\text { Khả năng đệm của } \\
\text { nước bọt }\end{array}$ & $4.57 \pm$ & 0.81 & 001 \\
\hline
\end{tabular}

Khi so sánh $\mathrm{pH}$ và khả năng đệm sau nhai kẹo cao su xilytol 5 phút, kết quả thấy có sự khác biệt có giá trị thống kê giữa $\mathrm{pH}$ và khả năng đệm $(p<0.01)$, với $p H$ nước bọt có giá trị trung bình $7.09 \pm 0.34$ và khả năng đệm là 4.57 \pm 0.81 . 


\section{BÀN LUÂN}

Trong nhóm nghiên cứu của chúng tôi, đối tượng là sinh viên trường Đại học $Y$ dược Thái Nguyên, điều này có thể giải thích có thể do đây là lứa tuổi trẻ, đồng thời sinh viên y chịu áp lực học tâp cao hơn tạo ra căng thẳng. Theo $\mathrm{C}$. Dawes và cộng sự [3], tâm lý căng thẳng có thể làm giảm dòng chảy nước bọt do tác dụng ức chế các trung tâm não chi phối các nhân nước bot.Bên canh đó, S. Wikner (1994) cho rằng tốc độ dòng chảy thấp có thể dự đoán giá trị khả nằng đệm thấp [8]. Nghiên cứu của Lucy $A$. Anderson và Robin Orchardson (2003) so sánh lưu lương và $\mathrm{pH}$ sau nhai keo cao su và sau khi nhai baking soda ( $\mathrm{NaHCO}$ ) cho thấy vai trò quan trọng của $\mathrm{HCO} 3$ trong sản phẩm hơn là tần suất nhai do nó có bổ sung thêm ion vào hệ thống đệm [6]. Nghiên cứu của chúng tôi chỉ nhai kẹo cao su xylitol đơn thuân nên ít có tác dụng lển hệ thống đệm hơn.

Phát hiện quan trọng nhất của nghiên cứu này có lẽ là sự tăng đáng kể lưu lượng của nước bọt làm tăng sự khác biệt giữa các thời điểm so sánh. Nghiên cứu của chúng tôi thực hiện trong 5 phút sau khi nhai kẹo. Tương tự như nhiều nghiên cứu, thời điểm 5 phút đầu tiên là thời điểm tăng lưu lượng nước bọt đáng kể nhất. $C$. Dawes và K. Kubnieniec (2004) thực hiện nghiên cứu trên 10 tình nguyện viên và kết luận lưu lượng nước bọt tăng tối đa và đạt đỉnh sau 5 phút rồi giảm dần [2]. Khi nhai kẹo cao su, ngoài tác dụng nhai để kích thích tuyển nước bọt, nó cón giúp phân phối xylitol, đầy nhanh quá trình rửa trôi axit trong miệng do tác dụng tăng lưu lượng dòng chảy của xyltitol. Cơ chế này là cơ chế nhận được sự ủng hộ của nhiều nghiên cứu để chứng minh vai trò của xylitol với sức khỏe răng miệng [7]. Bởi lẽ, khi lưu lượng nước bọt tăng sẽ giúp bể mặt men tiếp xúc với nhiêu yểu tố ion để tăng cường tái khoáng hóa bề mặt men

Đối với pH nước bọt, sau 5 phút, giá trị pH trong nghiên cứu của chúng tôi tăng so với ban đầu. Kết quả này khác với một số nghiên cứu đã được thực hiện. Cụ thể, một số nghiên cứu cho thẩy xylitol làm giảm $\mathrm{pH}$ chung của nước bọt trong những phút đầu tiên, giảm đáng kể từ phút thứ 5 đến phút thứ 10 [4] dù nó làm tăng $\mathrm{pH}$ mảng bám trong một thời gian dài - đây là tác dụng tích cực cho việc phòng ngừa sâu răng. Điều này quan trọng theo quan điểm lâm sàng, vì bệnh nhân thường được khuyên sử dụng kẹo cao su trong nửa giờ đầu tiên sau bữa ăn, khi mà lương axit tấn công sẽ đạt mức cao nhất trong miệng, và nếu ban đầu nước bọt có tính axit nhẹ, thì độ $\mathrm{pH}$ của nước bọt có thể dễ dàng giảm xuống dưới giá trị pH tới hạn là 5,5. Do đó, cần thận trọng khi lựa chọn biện pháp này cho việc phòng ngừa sâu răng, đặc biệt trên những đổi tượng có $\mathrm{pH}$ nước bọt thấp. Vì vậy, cần đánh giá cụ kỹ hơn thay đổi pH theo thời gian để nhận định rõ sự khác biêt này.

Những sự khác biệt của nghiên cứu của chúng tôi so với những nghiên cứu khác còn có thể là do tần số nhai trung bình của người Viêt Nam và nó cũng đặt ra câu hỏi về việc ngoài tác dụng của xylitol thì liệu tần số nhai có ảnh hương đến các đại lượng được đánh giá hay không. Câu trả lời cho bàn luận này thì cần được thực hiện trong những nghiển cứu sâu hơn để đánh giá sự tương quan giữa các thông số nghiên cứu.

\section{KẾT LUẬN}

Nghiên cứu này cho thãy do hiệu quả làm tăng lưu lượng, pH nước bọt sau khi nhai kẹo cao su xylitol nên sự khác biệt khi so sánh với khả năng đệm tăng iên so với ở trạng thái nghỉ. Tuy nhiên, nên có sự đánh giá thểm trong một thời gian để chứng minh rõ sự thay đổi.

\section{TÀI LIỆU THAM KHẢO}

1. Trướng Mạnh Dũng, Vũ Mạnh Tuấn. Thực trạng bệnh răng miệng và một số yếu tố liên quan ở trẻ 4-8 tuổi tại 5 tỉnh thành của Việt Nam năm 2010. Y Học Thực Hành. 2010; 797 (12): 56-59.

2. C. Dawes and K. Kubieniec. The effects of prolonged gum chewing on salivary flow rate and composition. Archives of oral biology. 2004; 49, 665-669.

3. C. Dawes and L. M. Macpherson. Effects of nine different chewing-gums and lozenges on salivary flow rate and $\mathrm{pH}$. Caries Research. 1992; 26 (3), 176-182, 1992.

4. Ivana Podunavac at all. Microfluidic Platform for Examination of Effect of Chewing Xylitol Gum on Salivary $\mathrm{pH}, \mathrm{O} 2$, and CO2. Applied sciences. 2021; $11,2049$.

5. Leone CW, Oppenheim FG. Physical and chemical aspects of saliva as indicators of risk for dental caries in humans. J Dent Educ. 2001; 65: 1054-1062.

6. Lucy A. Anderson, Robin Orchardson. The effect of chewing bicarbonate-containing gum on salivary flow rate and $\mathrm{pH}$ in humans. Archives of oral biology. 2003; 48, 201-204.

7. M Ribelles Llop. Effects of xylitol chewing gum on salivary flow rate, $\mathrm{pH}$, buffering capacity and presence of Streptococcus mutans in saliva. European Journal of Paediatric Dentistry. 2010; 11(1):9-14

8. S. Wikner. Factors associated with salivary buffering capacity in young adults in Stockholm, Sweden. Scand J Dent Res. 1994; 102(1):50-3). 